Article

\title{
Political Limits to the Processing of Policy Problems
}

Peter J. May ${ }^{1}$, Ashley E. Jochim ${ }^{2}$ and Barry Pump ${ }^{3}$

${ }^{1}$ Center for American Politics and Public Policy, Department of Political Science, University of Washington, 101 Gowen Hall, Campus Box 353530, Seattle, WA 98195, USA; E-Mail: pmay@u.washington.edu; Tel.: +1 2065432780; Fax: +1 2066852146

${ }^{2}$ Center on Reinventing Public Education, University of Washington, Seattle, WA 98109, USA; E-Mail: aew9@u.washington.edu

${ }^{3}$ Office of the Historian, U.S. House of Representatives, Washington, DC 20515, USA; E-Mail:

barry.pump@mail.house.gov

\section{How to Cite this Article}

May, P. J., Jochim, A. E., \& Pump, B. (2013). Political Limits to the Processing of Policy Problems. Politics and Governance, 1(2), 104-116.

\section{Acknowledgement}

This Article was published by Librello, Politics and Governance's former publisher.

\section{About the Journal}

Politics and Governance is an innovative new offering to the world of online publishing in the Political Sciences. An internationally peer-reviewed open access journal, Politics and Governance publishes significant, cutting-edge and multidisciplinary research drawn from all areas of Political Science.

www.cogitatiopress.com/politicsandgovernance

\section{Editors-in-Chief}

Professor Andrej J. Zwitter, Faculty of Law, University of Groningen, The Netherlands

Professor Amelia Hadfield, Department of Psychology, Politics and Sociology, Canterbury Christ Church University, UK

\section{Managing Editor}

Mr. António Vieira, Politics and Governance, Cogitatio Press, Portugal 


\title{
Political Limits to the Processing of Policy Problems
}

\author{
Peter J. May ${ }^{1, *}$, Ashley E. Jochim² and Barry Pump ${ }^{3}$ \\ ${ }^{1}$ Center for American Politics and Public Policy, Department of Political Science, University of Washington, \\ 101 Gowen Hall, Campus Box 353530, Seattle, WA 98195, USA; E-Mail: pmay@u.washington.edu; \\ Tel.: +1 2065432780; Fax: +1 2066852146 \\ ${ }^{2}$ Center on Reinventing Public Education, University of Washington, Seattle, WA 98109, USA; \\ E-Mail: aew9@u.washington.edu \\ ${ }^{3}$ Office of the Historian, U.S. House of Representatives, Washington, DC 20515, USA; \\ E-Mail: barry.pump@mail.house.gov \\ * Corresponding author
}

Submitted: 21 April 2013 | Accepted: 18 June 2013 | Published: 10 July 2013

\begin{abstract}
This contribution addresses political limits to the processing of policy problems in the United States. Our foci are the forces that limit policymakers' attention to different aspects of problems and how this affects the prospects for problem resolution. We theorize about three sets of forces: interest engagement, linkages among relevant institutions for policymaking, and partisan conflict. We show how the interplay of these forces limits efforts to address complex problems. Based on secondary accounts, we consider these underlying dynamics for ten complex problems. These include the thorny problems of the financial crisis, climate change, and health care; the persistent problems of K-12 education, drug abuse, and food safety; and the looming problems associated with critical infrastructure, the obesity epidemic, ocean health, and terrorism and extreme events. From these accounts we identify different patterns that we label fractured, allied, bureaucratic, and anemic policymaking.
\end{abstract}

Keywords: complex problems; policy processes; policymaking; problem attention

\section{Introduction}

Policymaking can be thought of as the conversion of demands into authoritative actions. The scholarly treatment of this spans two different traditions in the literature about American politics. One is the policy process tradition that follows David Easton's [1] depiction of a systems framework that considers the nature of the demands and policy outputs of the political system but leaves the details of the conversion process largely unspecified. The second tradition opens the black box by focusing on policymaking institutions and the processing of demands by presidents, legislatures, and the bureaucracy (see for example, [2-4]). The scholarship associated with both of these traditions is extensive though largely distinct. 
These traditions of literature overlap in addressing the organization of policymakers' attention for addressing policy problems. The policy process literature about agenda setting is concerned with the selection of demands for policy action. This literature underscores the multi-dimensional nature of most problems for which gaining policymaking attention to more-or-less agreed upon dimensions is a noteworthy hurdle. Jones and Baumgartner ([5], p. 208) suggest "attention allocation affects the choice of issues, the choice of issue characteristics, and the choice of solutions". But how is attention allocated? A number of scholars (see [6-8]) have argued that the structure of institutions-particularly committees in Congress and agencies in government-affects the channeling of attention towards different policy issues.

A central aspect of how attention is allocated is the interplay of issues and interests among different institutions for policymaking. This interplay is inherently political as various interest groups and partisans attempt to shape institutional agendas to reflect their concerns (see [9], pp. 49-57; [10]) within and across different venues for policymaking (see [11], pp. 228-231; [12], pp. 26-29). Fragmented issue attention frustrates the translation of demands into policies. Unless policymakers are more-or-less on the same page in addressing a given problem, it is difficult to move forward in crafting solutions for remedying the problem.

We examine the forces in American national politics that limit policymakers' attention to different aspects of problems and the prospects for problem resolution. Jones and Baumgartner's [5] information-processing theory of policymaking provides the foundation for our theorizing. They discuss how information overloads within policymaking institutions lead to a mix of selective and shifting attention across different problems and different dimensions of a given problem. In addressing these attention limits, we introduce more explicit consideration of the channeling of attention for a given problem within and across policymaking institutions.

Our argument is as follows. Many problems are multi-dimensional in that they are comprised of intertwined bundles of different issues and characteristics. As a consequence, policymakers must grapple with diverse problem formulations promoted by different policy advocates external to and within government. The degree to which interests are engaged and effectively articulate issues and solutions affects institutional agendas and the foci of policymakers' attention. Yet, how that attention is channeled as problems are processed within and across policymaking institutions differs. In particular, the way in which different aspects of a problem are parceled out and handed off to competing institutions either fosters or hinders policymakers' attention and eventual problem resolution. Fractured attention is especially noteworthy with highly partisan issues as policymakers divert attention through the strategic use of veto points that are built into policymaking institutions. We show how policy problems vary with respect to the interplay of interest engagement, the channeling of attention within institutions, and partisan conflict. This interplay, in turn, leads to different patterns of policymaking that limit policymakers' attention and the prospects for crafting agreed-upon remedies to policy problems.

\section{Conceptual Foundations}

The development of a shared understanding of a given problem is the essence of policymaking-what Heclo ([13], p. 305) refers to as "collective puzzlement on society's behalf". These shared understandings are shaped by a set of forces that channel policymakers' attention for addressing and resolving policy problems. The convergence in attention to particular dimensions of a problem is a critical element. Without such convergence, as argued by John Kingdon ([9], pp. 173-204), a policy window for taking action will not open. Simply put, policymakers need to be on the same page in order to address a given problem. Problems that have multiple, competing dimensions provide different paths for policymaking as advocates highlight different dimensions, different congressional committees claim jurisdiction, and conflicts arise over the aspects of the problem, if any, to be addressed. These dynamics fragment policymakers' attention and frustrate the potential for problem resolution.

We theorize that interest engagement with a given issue, the way that policymaking institutions are organized for the issue, and partisan conflict over it are key forces that limit the attention of policymakers and the prospects for problem resolution. We elaborate on these notions and the propositions related to them in what follows.

\subsection{Interest Engagement and Issue Attention}

What draws policymakers' attention to problems in the first place? Exogenous events that cannot be ignored, such as an oil spill or hurricane, are one set of influences (see [14], pp. 131-150; [9], pp. 99-105). But beyond such events triggering attention to problems, why does attention get channeled to some aspects of problems but not to others? For example, the Deepwater Horizon oil spill was about ocean health as much as it was about the fishing communities of the Gulf of Mexico. But in the wake of the disaster, policymakers' attention focused on BP's reparations to local economies. One truism of American politics is that problems are not addressed unless there are advocates for addressing them. Though such advocacy is not sufficient to compel action, it is almost always necessary. Without such advocacy, elected officials or other authoritative actors perceive little benefit in addressing a given problem, and there is a limited basis for crafting viable solutions. Advocates also provide rationales for action. 
Interest engagement clearly does not imply agreement among the interests about particular problem formulations or solutions. Interest advocates for different sets of issues often have different beliefs about the nature of the problem or solutions. As a consequence, they fall into what Sabatier and Weible [15] depict as opposing advocacy coalitions. Given divergence in beliefs, the likelihood of agreement on the relevant dimensions of a problem, or the preferred solutions, is low. In the face of such conflict, policymakers are reluctant to pick "winners" or "losers" in such debates unless they have a compelling rationale for doing so. These considerations lead to the proposition:

Proposition 1-Interest Engagement. Policymaking attention is fragmented by the presence of competing advocacy coalitions and weak policy communities.

This proposition gets at the makeup of the networks of interests (see [13]) and the extent to which they become politically relevant forces in drawing attention to a given dimension of a problem and providing a political rationale for addressing it (see [10]). Organized interests compete with each other in advancing issues, shaping problem formulations, putting forth preferred solutions, and lobbying policymakers (see [16]; [9], pp. 48-74). The important point from our perspective is how this is sorted out across issues rather than across interest groups. As Baumgartner and his colleagues empirically demonstrate ([16], pp. 128), some issues attract a lot of interest engagement while others receive little. Though focusing events like disasters and scandals are presumed to draw attention to particular issues, Birkland ([14], pp. 62-73) shows that this only happens in a sustained way when organized interests exist and are capable of capitalizing on the focusing event.

Weakly developed issue networks and policy communities characterize some issues (see [17]). As we show below, a variety of current policy problemscritical infrastructure, ocean health, and the threat of terrorism-have weakly developed publics. This results from insufficient incentives for groups to mobilize around the problem, as is especially the case with public goods. Without political mobilization that spans dimensions of a given problem, policymakers have a limited basis for taking policy action.

\subsection{Structure of Policymaking and the Channeling of Attention}

Policymaking institutions channel attention to issues differently. The ways these institutions shape how multi-dimensional problems-those that are comprised of intertwined bundles of different issues and characteristics-are processed is of particular interest (see [5], pp. 4-17). Climate change is as much about agricultural and forestry practices as it is about fossil fuel energy consumption.
Despite the potential for shifts in attention to the issues that are deemed important at any point in time, it is useful to remember that the allocation of attention across issues is highly organized within American policymaking institutions. Procedural rules formally define jurisdictions within Congress, though committees compete for turf (see [18]) and agencies have defined areas of expertise and reputations to defend [19]. As a consequence, the collective puzzling about problems is often parceled out in structured ways within and among policymaking institutions. This permits the efficient handling of large numbers of problems but also limits the treatment of complex, multidimensional problems. This is because different policymaking institutions (different committees in Congress and different agencies) focus on different dimensions or attributes of a given problem.

How attention is channeled for different attributes of a problem within and among policymaking institutions affects the foci of policymakers' attention. Of particular relevance is the degree to which actors in different policymaking institutions are connected and interdependent. We think of institutional interdependencies as the extent to which actors dealing with aspects of a given problem overlap or are linked through regular agency or committee interactions (see [20]), share ideas or policy goals as with boundary-spanning regimes (see [21]), or have "policy proximity" provided by shared policy tools or other features (see [22], p. 20). These institutional alignments condition patterns of attention, and at the same time they embody past patterns of political conflict and agreement. In this respect, the institutional channeling of attention is at least partially conditioned on prior patterns of policymaking for a given issue.

The distinction between serial and parallel processing of information is especially relevant (see [23]). Highly interdependent institutions are subject to serial processing of information as policymakers hand off problems through more-or-less regularized channels. Consider the financial crisis of 2008 that began as a banking crisis and rapidly cascaded into a crisis for insurance, securities and fiscal policy. Not only are these issues interrelated but the policymaking institutions that deal with them are tightly linked (see [24]). Actors in less interdependent policymaking institutions do not have patterns of interaction that establish regularized information flows among them. Contrast the financial crisis with the disruptions following the terrorist attacks of $9 / 11$ and subsequent policymaking. In studying the policy reverberations of the terrorism threat, May, Sapotichne and Workman [25] show that policymakers in different committees in Congress worked through their sense of the problem and viable solutions in a disconnected fashion.

Policymakers in interdependent institutions have advantages in forming policy responses to complex policy problems. Resolution of the problem becomes a shared undertaking as the fate of political actors 
becomes linked as a result of their common connections (see [26]). At the same time, the involvement of regularized sets of players leads to the treatment of problems in a similar manner to the past. This is because the "usual suspects" often wear blinders that limit the incorporation of new information and perspectives in problem processing. In other words, the structure of institutional interactions matters for how information about policy problems is processed. When a problem or event falls outside "standard operating procedure", interdependent institutions may lack the capacity to adapt their structure and respond in a timely manner. This leads to the following proposition:

Proposition 2a-Interdependent Institutions. Policymaking attention is constrained when highly interdependent institutions limit the capacity of policymakers to confront new or unexpected problems.

For example, in attempts to address the financial crisis of 2008, power coalesced around the Secretary of the Treasury and the Chairman of the Federal Reserve Board of Governors because the tightly knit congressional structure designed to deal with banking issues could not process all the elements of the crisis in a timely manner. In contrast to the "land rush" observed in other crises (see [27]), where committees with varying interests each tried to claim jurisdiction over a particular aspect of the problem, the financial crisis was characterized by a streamlined decisionmaking process with all the congressional stakeholders at, sometimes literally, the same table with administration and bureaucratic officials (see [28], pp. 442443). Despite the potential for turf wars due to overlapping jurisdictions (e.g., Financial Services with Judiciary on bankruptcy or Financial Services and Energy and Commerce on consumer issues), Congress essentially abdicated its oversight and policymaking functions at the height of the crisis, as evinced during the 2010 midterm elections when incumbents struggled to explain their votes for the Troubled Asset Relief Program and other bailouts.

Proposition 2b-Loosely-Linked Institutions. For problems processed in loosely linked institutions, policymaking attention is fragmented by institutional conflicts.

Institutional conflicts are more likely to arise when attention to problems is parceled out among less interdependent institutions. This is because actors in competing institutions (committees and agencies) attempt to define the dimensions of the problem at hand and available solutions to fit their purview (see [5], pp. 55-70; [9], pp. 99-105). Jurisdictional competition in Congress and within the bureaucracy acts as a disintegrative force as loosely-linked political institutions pull policymaking in different directions (see [11]; [29], pp. 193-215; [30]). External shocks like $9 / 11$ can lead to spillovers in attention as different players see connections between the focal event (e.g., an airplane crashing into the World Trade Center) and issues of concern to them (e.g., potential poisoning of the food supply). Yet, the attention is uneven across policymaking institutions given that they vary in their susceptibility to the disruption and ability to generalize from it. The net result of such institutional conflict is to increase the potential for impasse, delays, and disjunctions in policymaking.

\subsection{Partisan Conflict and Veto Points}

Policy problems differ in the extent to which they engender partisan conflict. Some problems such as the obesity epidemic and drug abuse are valence issues for which there is little debate about the desirability of acting but conflict over the role of government and appropriate interventions (more generally see [11], pp. 150-171). Other problems such as climate change engender varied patterns of partisan conflict over the problem and solutions. In generating a "heated up" policy space, partisan conflict fosters an unstable policymaking environment. Each set of competing issue dimensions presents opportunities for partisan policy entrepreneurs to take advantage of veto points that are built into the institutions of policymaking. Skillful use of these hurdles can frustrate policymaking. This leads to the following proposition:

Proposition 3-Partisan Conflict and Veto Points. Partisan conflict increases the strategic importance of veto points and fragments policymaking attention.

This proposition addresses the way that members of opposing political parties have increasingly taken advantage of the multiple veto points inherent in the American political system to frustrate policymakers' attention. This has expanded beyond the use of committee power in order to block bills in Congress. There has been increased use of procedural rules to modify the extent of debate and filibusters in the Senate to block policy enactment (see [31]). These mechanisms have both direct effects in delaying or blocking policy action and indirect effects in advocates' reshaping policy proposals in order to avert partisan use of procedural maneuvers. Daniel Carpenter ([32], p. 825) refers to the combined effect of this as "institutional strangulation" derived from "strategies of partisan intransigence".

Consider recent attempts to modify financial regulations in the wake of the 2008 crisis. The proposed new regulations spanned multiple issues from the size of banks to the creation of open exchanges for trading derivatives. In about a month and a half of consideration in the U.S. Senate, only a handful of contested votes did not fall largely along party lines. Indeed, even the definition of "financial company" was subject to a party-line vote (see [33]). This illustrates how partisan conflicts often begin as ideological disagreements but 
spill over into the more mundane aspects of policymaking when there are perceived electoral returns on disagreement.

We theorize that the effect of partisan intransigence in undermining problem resolution differs when issues are processed serially or in parallel. Under serial processing, where the resolution of issues is handed-off among connected policymaking institutions, any single veto point in the chain is a source of delay, if not blockage of problem resolution. Policy entrepreneurs must work hard to eliminate the veto points or to gain sufficient consensus to overcome them. Carpenter ([32], p. 828) discusses how this played out for financial reform in the Obama Administration in documenting how provisions in the House bill were "watered down and in some cases abjectly voted down" by those promoting reform in order to press ahead. Moreover, Carpenter ([32], p. 830) suggests that the associated policy networks and agencies that are tightly linked in financial policymaking form less formal veto points: "the veto points are not necessarily those of Congress, but those of administrative and advisory politics. In this networked world, ideas are more likely to disappear from the agenda not with research, but because they are deemed outside of the set of 'legitimate' ideas".

Partisan forces are also at work for the parallel processing of issues. But here the structure of policymaking works to limit the importance of a single veto point and enables "work arounds". Consider the evolution of homeland security policy after the terrorist attacks of 11th September 2001. Policymakers in different committees in Congress worked through their sense of the problem and viable solutions in a disconnected fashion, which led to the creation of issue-specific legislation such as the creation of the Transportation Security Administration for transportation security [34] and passing the Public Health Security and Bioterrorism Response Act of 2001 [35] for biosecurity. This is far different than creation of a comprehensive homeland security reform. Even when that came later with the enactment of the Homeland Security Act of 2002 [36], numerous-largely disconnected-committees in Congress were involved, leading to both the kind of turf fights we cite above as endemic to parallel processing and also the piecemeal patching together of different provisions (see [37], pp. 689-700).

\section{Varieties of Problems}

We examine ten complex problems in order to characterize the interplay of interest engagement, institutional channeling of attention, and partisan politics in limiting policymakers' attention to particular dimensions of a problem and resultant problem resolution. We selected these cases with several considerations in mind. We only selected contemporary domestic problems. This provides a current perspective rather than a historical one. In order to provide meaningful comparisons, we selected cases to ensure sufficient variation among the three forces we consider. We also sought cases that reflected different problem areas. Finally, we sought cases for which there is an available academic and policy literature that depicts the politics surrounding the problem and efforts to resolve it. This included a review of relevant scholarly literature in political science and public administration, policy digests by government analytic agencies (mainly Congressional Research Service, General Accountability Office), and policy digests by independent sources (mainly CQ Researcher and CQ Almanac).

Our evidence for the political processing of these is drawn from the secondary accounts. For each case, we developed a profile that characterized the nature of the problem and evidence for linkages among relevant policymaking institutions, the engagement of different publics, and the extent and forms of partisan conflict surrounding the problem and its resolution. These assessments are necessarily impressionistic because of the variation with which the source material addresses the characteristics of interest for our research.

We assessed institutional linkages by looking for evidence of commonalities among committees in Congress, the White House, and the bureaucracy when they addressed the problem or considered solutions. An example of stronger linkages is the interplay between the Treasury Department, Federal Reserve, and Congressional banking committees in addressing the cascading effects of the fiscal crisis. An example of weaker linkages is the parallel policy development among different sectors for addressing the protection of critical infrastructures.

We assessed the degree of engagement of different interest groups and other policy publics when they addressed each problem or advocated solutions. The extent to which these groups advocated for similar problem formulations and solutions is of particular relevance. Finally, we considered various aspects of partisan conflict. The degree of partisan conflict is affected by the extent of ideological polarization and the electoral importance of an issue for the majority party's legislative coalition. Electoral importance is a significant dimension of partisan conflict because it affects a majority coalition's willingness to address an issue (i.e., put it on the agenda) and the opposing party's willingness to counter-mobilize and draw potentially advantageous distinctions. Health care reform illustrates this as ideological polarization between political parties is exacerbated by the electoral significance of the issue, which results in an unusually high degree of conflict. Issues characterized by the weakest degree of partisan conflict demonstrate little polarization and are low among the parties' policy priorities while issues characterized by the greatest degree of partisan conflict are both highly polarizing and key electoral issues.

Relevant features of the different policy problems we considered are arrayed in Figure 1. 


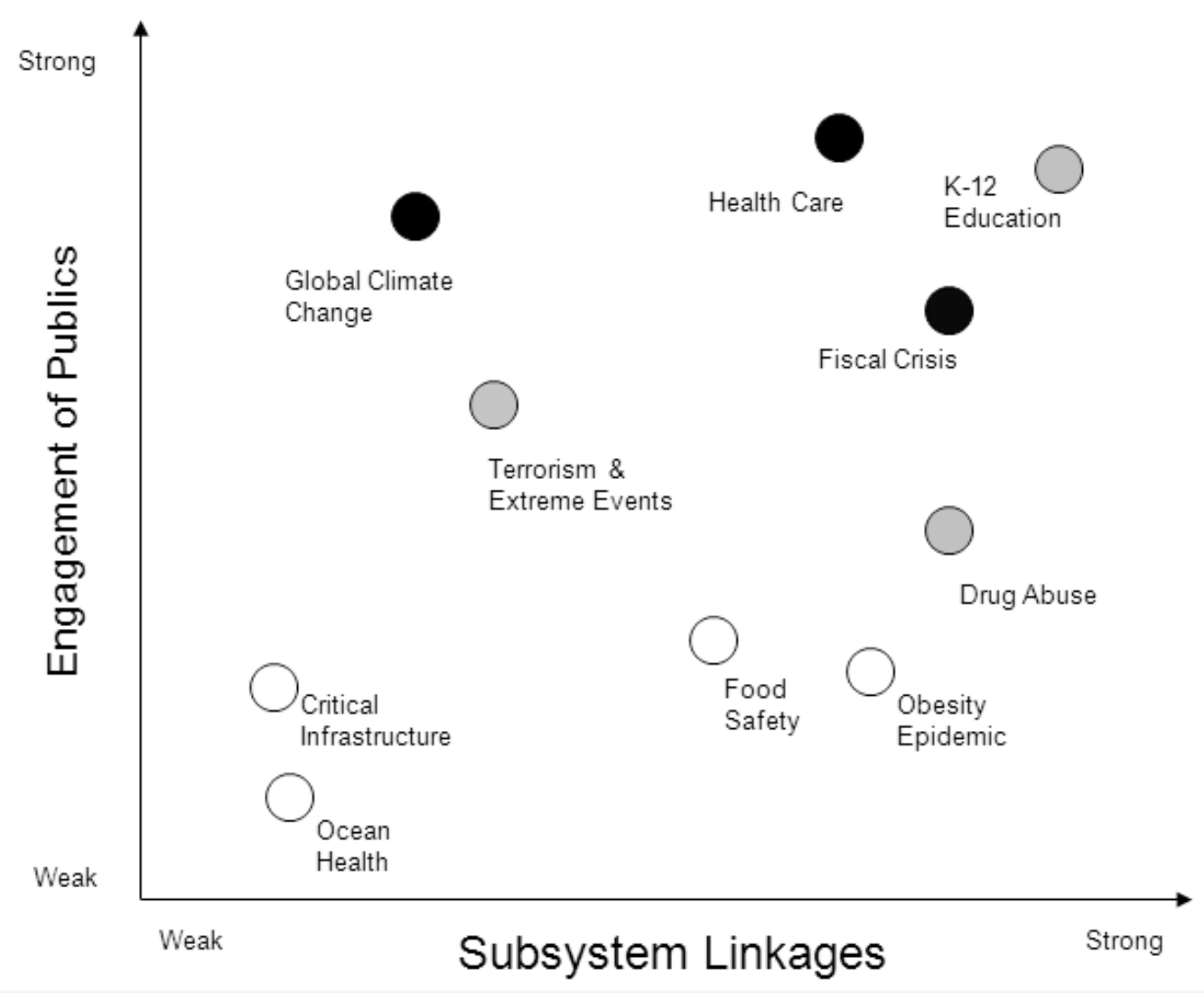

Figure 1. Policymaking features of selected policy problems. Circles indicate the degree of partisan conflict over an issue or solution-darker shading indicates greater conflict.

The horizontal axis depicts the strength of linkages among relevant institutional actors, keeping in mind that the number of relevant institutions (i.e., committees in Congress, federal agencies) varies among the selected problems. The vertical axis depicts the strength of engagement of different interests. The shading of the circles next to each issue label indicates the extent of partisan conflict with darker circles depicting greater conflict. Given the imprecision of measuring each of these, it is best to consider the location of each problem as a relative comparison rather than an absolute one.

Several points stand out from this comparison. One is the variation in the political and policymaking characteristics of these problems. Some, such as health care and K-12 education, have well-established policymaking venues with engaged publics and moderate to high degrees of partisan conflict. Others, like critical infrastructure and ocean health, are more disconnected in their policy treatment with limited engagement of policy publics and low levels of partisan conflict. A second observation is that nearly three-quarters of the problems can be labeled valence issues involving the lessening of harms. Yet, unlike typical valence issues, there is partisan debate for a number of these problems about the extent and timing of future harms and thus the need to act now or in a comprehensive fashion. Contrast the immediacy and the rush to act during the financial crisis with the more glacial approach and uncertainties surrounding approaches to addressing global climate change. A third observation is the interplay of partisan conflict with the other dimensions we consider. Higher degrees of partisan conflict are associated with stronger engagement of publics, perhaps reflective of the increased salience of the issues and the more entrenched beliefs about the problem or solutions. The strength of institutional linkages appears to be only loosely related to partisan conflict.

The cases suggest four broad patterns of policymaking. Those that fit within each pattern are identified by dividing each axis in two so as to provide four quadrants: Two cases in the upper left (climate change and terrorism and extreme events), three in the upper right (economic crisis, health care, and K-12 education), three in the lower right (drug abuse, food safety, obesity epidemic), and the remaining two cases in the lower left (ocean health and critical infrastructure). Based on our reading of the secondary literature concerning these problem areas, we identify four fairly distinctive policymaking patterns. It is important to recognize that there is variation among cases within each of these quadrants in part due to differences in the extent of partisan conflict. The policymaking patterns and resultant limits to problem resolution are summarized in Table 1 and elaborated in the following discussion. 
Table 1. Policymaking patterns and their limits.

\begin{tabular}{|c|c|c|c|}
\hline & \multicolumn{2}{|c|}{ Institutional Linkages } \\
\hline & & Weak & Strong \\
\hline \multirow{8}{*}{$\begin{array}{l}\text { Engagement } \\
\text { of Publics }\end{array}$} & \multirow{4}{*}{ Strong } & Fractured Policymaking & Allied Policymaking \\
\hline & & - High salience & - High salience \\
\hline & & - Disintegrative politics & - Coalition politics \\
\hline & & - Partial resolution & - Unstable resolution \\
\hline & \multirow{4}{*}{ Weak } & Anemic Policymaking & Bureaucratic Policymaking \\
\hline & & - Low salience & - Low salience \\
\hline & & - Seemingly apolitical & - Turf politics \\
\hline & & - Lacking resolution & - Deferred resolution \\
\hline
\end{tabular}

\subsection{Fractured Policymaking}

The two cases in the upper left quadrant comprise what we label fractured policymaking; marked by highly engaged interests that emphasize different aspects of a given problem, moderate to high partisan conflict, and weak institutional linkages. The strong engagement of publics increases the salience and political stakes of these issues, adding to their fractured politics. The disorganized and haphazard issue attention is a result of weak institutional linkages and the parallel processing of different issue attributes among different institutions (especially committees in Congress). The result is attention to a particular dimension of a problem rather than to the interplay of multiple dimensions. These dynamics are evident from considering the two cases in this quadrant.

Most discussions of climate change highlight the interplay of the physical and socio-economic dimensions of the evolving problem, the uncertainty over the extent of the problem, and the difficulties of projecting future impacts (see [38]). For our purposes, however, the important considerations are the political and policymaking limits to addressing the problem in an integrative fashion. We attribute failure to achieve comprehensive approaches in the United States to the forces that undermine problem resolution. One is the weak ties among relevant actors in different policymaking institutions (primarily different congressional committees), which consider different aspects of the problem-principally, Agriculture, Energy and Commerce, Natural Resources, Small Business, and Taxation (see [39]). In essence, policymakers are acting in parallel with different agendas, timelines, and foci. By definition, this fragments attention. Second, the extensive engagement of different coalitions addressing aspects of the problem and advocating solutions undermines reform efforts. As discussed by McCright and Dunlap [40], this was especially evident in the efforts of different coalitions to defeat the ratification of the Kyoto Protocol. The third force, which has been noteworthy for limiting the enactment of reforms, is the high degree of partisan conflict at national levels over climate change issues. Dunlap and McCright [41] document the partisan split in the general public and within Congress, as Republicans are increasingly reluctant to address the problem.

The terrorist attacks of 11th September 2001 clearly elevated the threat of terrorism on the policy agenda and focused policymakers' attention to that threat and potential spillover concerning such things as the safety of the food supply and threats to public health. May, Sapotichne and Workman [25] empirically demonstrate the policymaking responses to these threats were highly disjunctive in that different congressional committees worked through their sense of the problem and viable solutions in a disconnected fashion. The end result was a set of policies that reflected the different agendas, constituencies, and political concerns of the various committees and federal agencies that addressed different risks. The creation of the Department of Homeland Security provided a hobbled approach to coordinating these efforts with an agency that was stitched together in a haphazard manner (see $[42,43])$. The failures of the response to Hurricane Katrina highlighted the singular focus of the homeland security efforts on terrorism at the expense of ignoring the threats posed by natural and technological disasters. The end result of this policymaking is what May, Jochim and Sapotichne [44] characterize as a weak policy regime. Despite the evident limits of this regime, the homeland security apparatus has been sustained politically by partisan coalitions in Congress who benefit from fomenting concerns about terrorism (more generally see [45], pp. 78-110).

\subsection{Allied Policymaking}

The three cases in the upper right quadrant comprise what we label allied policymaking; marked by high salience and fairly contentious partisan conflict, but supportive reform coalitions. Partisan politics strongly influenced these issues as they were mainly serially processed within interdependent policymaking institu- 
tions. The result is what we label unstable problem resolution. In each instance the problems narrowed$\mathrm{K}-12$ education focused on accountability, health care focused on access (as opposed to cost reduction), and financial reform focused on stability (with less attention to systemic risk). This narrowing allowed for policymaking around key aspects of each problem while also disappointing advocates concerned with other problem aspects, thereby undermining the reforms. For the cases of health care and financial reform, the partisan use of veto points led to further instability, which resulted in adjustments that weakened the reforms. These dynamics are evident from considering each of the three cases in this quadrant.

The politics and policymaking for $\mathrm{K}-12$ education is marked by a fairly stable policy community that has operated for decades at the federal, state, and local levels involving key players like teachers' unions, experts and researchers, civil rights organizations, and bureaucrats. Though there have been sharp divides among the players over a range of $\mathrm{K}-12$ issues (see [46]), reform coalitions have formed at various points in time among key allies within the $\mathrm{K}-12$ policy community-most notably for the enactment of No Child Left Behind in 2001. In this regard, Paul Manna [47] discusses how the sharing of ideas and the linkages across different venues of policymaking fostered changes in the national education agenda along with a narrowing of that agenda. Patrick McGuinn [48] advances this understanding by showing how the power of ideas such as accountability, standards, and testing took hold at a time of increased concern about educational performance. As attention converged on accountability, reformers largely overcame traditional bases of opposition. Presidential advocacy provided additional momentum for accountability-based reform. All of this was accomplished in a bipartisan manner, although this masked the underlying disorder generated by conflicts involving teachers' unions, some state governors, and other educational reform advocates. The subsequent backlash to K-12 accountability underscores the fragility of such coalitions (more generally see [49], pp. 29-33).

The saga of health care reform, which began in the run-up to the 2008 election and continued through the enactment of comprehensive reforms in March 2010, epitomizes the political and policymaking complexities of allied policymaking. The long history of failed health care reforms in the United States is, as David Wilsford [50] points out, marked by powerful government institutions and conflicting interests (also see [51]). Theda Skocpol's [52] insightful depiction of the failures of the Clinton health care reform further underscores the challenges of creating a reform coalition in Congress and a strong constituency for a particular plan. As analyzed by Jacob Hacker [53], the quest for consequential reform seemed to define the Obama administration's efforts to avoid the pitfalls of the Clinton reform and Congress's efforts to craft a viable coalition in support of increasingly less-comprehensive reforms-albeit with shifting definitions of what constituted meaningful reform. In essence, the "comprehensive" reform became a "stitched-together" reform in search of a viable allied coalition. A major constraint throughout was the partisan divide in Congress over reform, which continues today with promises by conservative Republicans to dismantle the enacted reforms.

The regulatory overhaul of the financial system in 2010 further illustrates allied politics with the added pressures of an extraordinary crisis in the global financial system. Banks stopped lending and the problems facing the financial industry led to the worst economic downturn since the Great Depression. In this regard, the effects of the problem were widely felt, to put it mildly. Yet, the policymaking that ensued did not reflect this degree of disruption, as linked-players within the banking, finance, and securities subsystems engaged in serial processing of the problem. Perhaps more than for any other contemporary problem, these players were acutely aware of their "shared fate" in crafting reform. As Congleton [54] notes, policymaking to deal with the financial crisis and its underlying causes was remarkably routine given how the urgency of the crisis permeated the discourse and decision making of policy actors. Williams [55] suggests this is due to the tight linkages among relevant players with few new players entering the policy discussion. As discussed by Carpenter [32], competing ideological visions for the role of government in the economy dominated the partisan conflict over policy responses. Minority-party Republicans perceived electoral returns on disagreement with majority-party Democrats, and the high level of polarization led to tremendous gridlock but for a small group of moderate Republicans who made increasingly less-comprehensive reform possible.

\subsection{Bureaucratic Policymaking}

The three cases in the lower right quadrant comprise what we label bureaucratic policymaking; marked by moderate to low partisan conflict that plays out mostly in the policymaking backwaters, occasional high-level attention, and reliance on experts to drive policy change. The weaker engagement of publics reflects the generally low salience of these issues. As a consequence, the subject matter experts within government and specialized organizations that follow the issues provide the impetus for action and the sources of policy reform, which results in policymaking that is deferred, but not explicitly delegated, to the administrative branch. At times, as with each of the cases we consider, there is higher-level intervention on the part of presidents seeking coordinated action among President agencies. Though Congress has been involved in holding hearings and considering reforms, most of the policymaking for these issues has involved new regulations or administrative efforts to better co- 
ordinate agency actions. These dynamics are evident from considering each of the three cases in this quadrant.

The politics of drug abuse policy is not as straightforward as it appears. On the one hand, it is a classic macro-political issue driven by presidential initiatives that began in 1971 with Nixon's War on Drugs and continued as a mainstream aspect of presidential politics in future elections (see [56]; [57], pp. 34-73). Few political actors seem to be able to resist punitive attitudes given the dynamics of a highly salient issue coupled with a weak and powerless target group. However, as much as macro political attention seems to dominate efforts to define the drug problem, there is also an "inside-the-beltway" component driven by the prominent role that federal, state, and local criminal justice bureaucrats play in policymaking (see [58]). As shown by Meier and Smith [59], the durability of drug use criminalization has been reinforced by the powerful set of interlocking federal, state, and local enforcement agencies, with strong federal funding and access at local levels to asset seizures made under the Crime Control Act of 1984. The countervailing forces of public health advocates who argue for drug treatment programs have gained traction at various points in time, but they are generally politically weaker than the criminal justice advocates.

The safety of food in the United States is a problem that receives episodic attention in the aftermath of different scares which attract media attention. Beginning with the Meat and Poultry Act of 1906, which followed Upton Sinclair's depiction of the stockyards of Chicago, food safety has been marked by a patchwork system of laws, regulations, and responsible authorities, which largely grew out of efforts to address specific health threats from particular food sources, rather than some coherent, over-arching master plan (see [60]). There have been presidential and congressional efforts to bring about comprehensive reform of food safety regulation (see [61]). The most notable among these was the long-sought passage of the Food Safety and Modernization Act in 2010 [62]. Though the reform is notable in giving the FDA expanded powers and reducing the bureaucratic confusion in food safety inspection, the same forces that conspired to impede prior reforms worked to limit key aspects of the 2010 reform. Chief among these are a powerful industry alliance of food producers and packers that has raised concerns about the costs of reforms and challenged new regulations in the courts (see [63]). Consumer and environmental groups have had only limited effectiveness in advocating for reforms. Given the insufficient political basis for comprehensive reform, change has been typically accomplished through the regulatory process. The exception is the 2010 reform that was blocked in the Senate for over a year, but pushed through with a bipartisan Senate vote (73-25) in the wake of a massive recall of more than a half-billion tainted eggs. Reform advocates were able to take advantage of this although the reform will take years to implement and depend on additional funding to carry it out.

The problem of obesity has received much attention in the media and health circles in recent years in the United States. Despite increased attention to the problem by public health advocates, there appears to be little concern on the part of the broader citizenry and traditional ideological or partisan divisions do not seem to apply at national levels (see [64]). As in the politics of food safety, strong food industry interests and their supporters have muted advocates for comprehensive policy (see [65]). States and localities have filled the void with a patchwork of regulatory actions. But, as noted by social policy observers Kersh and Morone [66], gaps and regulatory inconsistencies have led advocates to renew calls for coherent national approaches. As for the drug abuse and food safety problems, high-level executive branch intervention-in this case a White House Task Force led by Michelle Obama-has attempted to bring about greater policy coherence for addressing childhood obesity. That initiative sets a goal of solving the problem of childhood obesity in a generation, commits federal agencies to a number of administrative actions in support of that goal, and establishes a variety of partnerships with advocacy and private-sector organizations.

\subsection{Anemic Policymaking}

The remaining two cases in the lower left quadrant comprise what we label anemic policymaking because of the lack of impetus for addressing them and a limited basis for problem resolution. Sustained attention to such issues is typically limited to narrow policy communities around vague problem conceptualizations. These are the most difficult problems to address from a political perspective. The difficulties arise from several sources. One is the disconnection between players addressing aspects of the problem. Absent macro-political intervention by presidents or congressional leaders, usually in the wake of a major crisis, there is little basis for agreement about the problem or its resolution. Even in the aftermath of major crises, reform efforts can be piecemeal and shortlived. Unlike allied policymaking, there is little basis for forming an effective coalition in support of reform. Like bureaucratic policymaking, these issues are largely within the domain of substantive policy experts. The relative lack of partisan conflict might be viewed as positive. Yet the lack of broader-based publics undermines the impetus for action. These dynamics are evident from considering aspects of the three cases in this quadrant.

Though two major commissions have recently highlighted the seriousness of the decline of ocean health -the Pew Oceans Commission [67] and the U.S. Commission of Ocean Policy [68]-progress in addressing this problem has been halting and piecemeal. The Pew Oceans Commission report ([67], p. viii) suc- 
cinctly states: "plagued with systemic problems, U.S. ocean governance is in disarray". The disarray reflects the institutional layering of responsibilities ranging from environmental conditions, to fisheries management, to international trade that the Pew report notes constitute more than 140 laws involving at least six cabinet-level departments and dozens of agencies.

But why has such reform been stymied, given the seeming consensus about the need for it? The answer, we argue, is the lack of engagement among a broaderbased set of publics. In this regard, Sarah Chasis ([69], p. A20) of the Natural Resources Defense Council notes that progress is stymied by "too few ocean champions on the Hill, the lack of a strong administration leadership, tight budget times, and a lack of public awareness". At the same time there has been little partisan or interest group conflict over the need to address these problems. The lack of partisanship is evinced by Bush administration appointments to the U.S. Commission on Ocean Policy and by the Obama administration's formation of the National Ocean Council for coordinating governmental programs. Though these issues have reached the presidential agenda, they are notably absent from the congressional agenda. As suggested by the actions of the Obama administration, future change for ocean policy may look more like bureaucratic policymaking than reform policymaking.

Attention to the security of the nation's critical infrastructure-banking and communications, chemical plants, energy facilities, government facilities and other "critical assets"-has also been dominated by presidential actions, beginning in 1996 with President Clinton's appointment of the Commission on Critical Infrastructure Protection. Subsequent documents have had varied definitions of what constitutes critical infrastructure involving a plethora of different federal, state, and private entities (see [70]). The engagement of different interests has been very uneven and highly disbursed among the different types of critical facilities that are designated within the federal "partnership plan" for addressing critical infrastructure. This unevenness undermines the ability to bring about coordinated action in support of a national approach to the problem. As noted by Myriam Dunn ([71], p. 260), in discussing one aspect of the problem, critical information protection "has become an issue of high relevance to many different, very diverse, and often overlapping communities. These different groups, be they private, public, or a mixture of both, usually do not agree on the nature of the problem or on what needs to be protected. Depending on their influence or on the resources at hand, various key players shape the issue in accordance with their view of the problem". Here the limits are as much within the private sector as they are within the public sector. As with ocean policy, the politics of infrastructure protection are played out by experts and with little or no partisan rancor. The result is a policy path defined by bureaucratic inertia around "partnership planning" that has evident disjunctions.

\section{Conclusions}

The preceding discussion helps to identify the forces in American politics which conspire to fragment policymakers' attention to different aspects of problems and thereby limit the prospects for problem resolution. Perhaps the most important point is that these forces vary considerably in their significance for different types of problems. Fractured policymaking, as found for climate change and the threat of terrorism, is marked by disintegrative politics, moderate to strong partisan conflict, and partial policy resolution. Allied policymaking, as found for the financial crisis, health care, and $\mathrm{K}-12$ education, is marked by high salience, fairly contentious partisanship, and unstable policy resolution. Bureaucratic policymaking, as found with the national drug abuse problem, lapses in food safety, and the obesity epidemic, is marked by moderate to low partisan conflict, reliance on experts and bureaucrats as the drivers of policy change, and deferred policy resolution to the administrative branch. Anemic policymaking, as found for the problems of declining ocean health and the vulnerability of critical infrastructures, is marked by low salience, weak and insufficiently developed publics, low to moderate partisan conflict, and a limited basis for policy resolution.

Each pattern of policymaking suggests a different challenge for achieving policy resolution. Problems that are characterized by fractured policymaking and are hampered by partisan conflicts can be especially difficult to overcome. Any prospect for reform would seem to rest on effective coalition building as the examples of allied policymaking-financial reform, health care reform, and $\mathrm{K}-12$ education-demonstrate. Yet such reform policymaking entails transitory and unstable coalitions that can dissolve and weaken the political basis for the reforms, as discussed by Eric Patashnik ([49], pp. 29-33). Bureaucratic policymaking suffers from the inability to "lock in" policy changes without legislative action. The challenges of anemic policymaking are particularly acute in that they lack the interest bases for mobilizing action and tend to fall through institutional cracks.

This discussion raises at least two considerations that merit consideration in future research. One is the mechanisms for, and patterns in, the transformation of problems from one category of policymaking to another over time-in other words, the political dynamics of problem processing. We have hinted at how some problems (health care in particular) have moved from the realm of fractured policymaking to allied policymaking. Here, the keys were coalition building in support of more comprehensive policy. But clearly that is difficult to achieve and any such coalition is likely to be highly unstable. In this case, as in financial sector reform, the degree of comprehensiveness waned as 
the process played out. Problems characterized by bureaucratic policymaking take on new dynamics with macro-political involvement, as illustrated by the 2010 reforms in food safety. Such transformations in bureaucratic policymaking tend to be episodic and driven by focusing events, as illustrated by the massive egg recall in 2010, prompting food safety reform. We also suggest that presidential administrative reforms have the potential for converting anemic policymaking to bureaucratic policymaking. This is illustrated by the treatment of food safety in the past and the emerging federal steps in addressing the obesity epidemic. But we noted that such actions are limited in that they do not provide the necessary constituency or political support to be durable reforms.

A second future research direction gets at the reasons why the political processing of problems take the forms that they do. We have identified the policymaking patterns for various problems and the elements that comprise each pattern, but we have not established how these patterns come about. Put differently, the patterns of policymaking do not occur by happenstance. Different interests may be well served by keeping the treatment of a given problem anemic or on the back burner of government. Why, for example, have the well-recognized problems associated with declining ocean health not been addressed? Or why was the fractured system of monitoring the safety of

\section{References}

1. Easton D. An Approach to the Analysis of Political Systems. World Politics. 1957;9(3):383-400.

2. Baumgartner FR, Jones BD, MacLeod MC. The Evolution of Legislative Jurisdictions. The Journal of Politics. 2000;62(2):321-349.

3. Jones BD, Sulkin T, Larsen HA. Policy Punctuations in American Political Institutions. American Political Science Review. 2003;97(1):151-169.

4. May PJ, Workman S, Jones BD. Organizing Attention: Responses of the Bureaucracy to Agenda Disruption. Journal of Public Administration Research and Theory. 2008;18(4):517-541.

5. Jones BD, Baumgartner FR. The Politics of Attention. Chicago, IL, USA: University of Chicago Press; 2005.

6. Arrow KJ. The Limits of Organization. New York, NY, USA: W. W. Norton and Company; 1974.

7. Hammond TH. Agenda Control, Organizational Structure and Bureaucratic Politics. American Journal of Political Science. 1986;30(2):379-420.

8. Krehbiel K. Information and Legislative Organization. Ann Arbor, MI, USA: University of Michigan Press; 1991.

9. Kingdon JW. Agendas, Alternative, and Public Policies. Glenview, IL, USA: Scott, Foresman and Company; 1984.

10. Stone DA. Causal Stories and the Formation of food that way for so long? In these and other similar circumstances, it is evident that some interests benefit from more limited policy actions. These same forces are likely at work in establishing and maintaining the institutional arrangements that channel policymaking attention in particular ways either to foster or fragment uniformity in attention.

Consideration of how fundamental forces in American politics limit the treatment of different problems adds new insights for the study of public policy. As this contribution suggests, two lines of inquiry are especially relevant: how attention is channeled into different dimensions of problems within and across policymaking institutions and how interest-based and partisan politics are both affected by the channeling of policymaking attention and help to limit it.

\section{Acknowledgements}

The development of this paper has benefited from comments and other assistance provided by Frank Baumgartner, Christopher Green-Petersen, Asaph Glosser, John Griswold, Hank Jenkins-Smith, Chris Koski, Nick Stramp, Paul Posner, Rebecca Thorpe, and John Wilkerson. Financial support for this research was provided by National Science Foundation grant number CMMI-0925306. Neither the NSF nor the organizations for which the authors work are responsible for the content of this manuscript.

Policy Agendas. Political Science Quarterly. 1989;104 (2):281-300.

11. Baumgartner FR, Jones BD. Agendas and Instability in American Politics. Chicago, IL, USA: University of Chicago Press; 1993.

12. Pralle SB. Branching Out, Digging In: Environmental Advocacy and Agenda Setting. Washington, DC, USA: Georgetown University Press; 2006.

13. Heclo $H$. Issue Networks and the Executive Establishment. In: King $A$, editor. The New American Political System. Washington, DC, USA: American Enterprise Institute; 1974. pp. 87-124.

14. Birkland TA. After Disaster: Agenda Setting, Public Policy, and Focusing Events. Washington, DC, USA: Georgetown University Press; 1997.

15. Sabatier P, Weible C. The Advocacy Coalition Framework, Innovations and Clarifications. In: Sabatier $\mathrm{P}$, editor. Theories of the Policy Process. 2nd ed. Boulder, CO, USA: Westview Press; 2007. pp. 189-220.

16. Baumgartner FR, Berry JM, Hojnacki $M$, Kimball DC, Leech BL. Lobbying and Policy Change: Who Wins, Who Loses, and Why. Chicago, IL, USA: University of Chicago Press; 2009.

17. May PJ. Reconsidering Policy Design: Policies and Publics. Journal of Public Policy. 1991;11(2):187-206.

18. King DC. Turf Wars: How Congressional Committees Claim Jurisdiction. Chicago, IL, USA: University of Chicago Press; 1997. 
19. Carpenter DP. Reputation and Power: Organizational Image and Pharmaceutical Regulation at the FDA. Princeton, NJ, USA: Princeton University Press; 2010.

20. Zafonte M, Sabatier PA. Share Beliefs and Imposed Interdependencies as Determinants of Ally Networks in Overlapping Subsystems. Journal of Theoretical Politics. 1998; 10(4):473-505.

21. Jochim AE, May PJ. Beyond Subsystems: Policy Regimes and Governance. Policy Studies Journal. 2010; 38(2):303-327.

22. Nohrstedt D, Weible CM. The Logic of Policy Change after Crisis: Proximity and Subystem Interaction. Risk, Hazards \& Crisis in Public Policy. 2010;1(2): 1-32.

23. Workman $S$, Jones $B D$, Jochim $A E$. Information Processing and Policy Dynamics. Policy Studies Journal. 2009;37(1):75-92.

24. Khademian A. Bankruptcies, Bailouts and the Banking Bureaucracy: The Bush Agenda and the Capacity for Crisis. The Forum. 2009;7(4):1-19.

25. May PJ, Sapotichne J, Workman S. Widespread Policy Disruption: Terrorism, Public Risks, and Homeland Security. Policy Studies Journal. 2009;37(2):171-194.

26. Grant W, MacNamara A. When Policy Communities Intersect: The Case of Agriculture and Banking. Political Studies. 1995;43(3):509-515.

27. Jones CO, Strahan R. The Effect of Energy Politics on Congressional and Executive Organization in the 1970s. Legislative Studies Quarterly. 1985;10(2): 151-179.

28. Sorkin AR. Too Big to Fail: The Inside Story of How Wall Street and Washington Fought to Save the Financial System-And Themselves. New York, NY, USA: Viking; 2009.

29. Alder ES, Wilkerson JW. Intended Consequences: Jurisdictional Reform and Issue Control in the U.S. House of Representatives. Legislative Studies Quarterly. 2008;33(1):85-112.

30. Nicholson-Crotty S. Bureaucratic Competition in the Policy Process. Policy Studies Journal. 2005;33 (3):341-361.

31. Theriault SM. Party Polarization in Congress. New York, NY, USA: Cambridge University Press; 2008.

32. Carpenter D. Institutional Strangulation: Bureaucratic Politics and Financial Reform in the Obama Administration. Perspective on Politics. 2010;8(3):825846.

33. Senate Amendment 3898 to S. 3217 offered by Sen. Ensign of Nevada and roll call 135 on 6 May 2010.

34. U.S. Public Law 107-71. 19 November 2001.

35. U.S. Public Law 107-188. 12 June 2002.

36. U.S. Public Law 107-296. 25 November 2002.

37. Cohen DK, Cuellar MF, Weingast BR. Crisis in Bureaucracy: Homeland Security and the Political Design of Legal Mandates. Stanford Law Review. 2006;59(3):673-759.

38. Hempel LC. Greenhouse Warming: The Changing Climate in Science and Politics: A Review Essay.
Political Research Quarterly. 1993;46(1):213-239.

39. Selin $H$, VanDeveer SD. Political Science and Prediction: What's Next for U.S. Climate Change Policy. Review of Policy Research. 2007;24(1):1-27.

40. McCright AM, Dunlap RE. Defeating Kyoto: The Conservative Movement's Impact on U.S. Climate Change Policy. Social Problems. 2003;50(3):348-373.

41. Dunlap RE, McCright AM. A Widening Gap: Republican and Democratic Views on Climate Change. Environment: Science and Policy for Sustainable Development. September/October 2008. Available from: http://www.environmentmagazine.org/Archives/Back\% 20Issues/September-October\%202008/dunlap-full.html (accessed on 18 April 2013).

42. Kettl DF. Contingent Coordination: Practical and Theoretical Puzzles for Homeland Security. American Review of Public Administration. 2003;33(3):253-277.

43. Wise CR. Organizing for Homeland Security after Katrina: Is Adaptive Management What's Missing? Public Administration Review. 2006;66(3):302-317.

44. May PJ, Jochim AE, Sapotichne J. Constructing Homeland Security. Policy Studies Journal. 2011;39 (2):285-307.

45. Goodin RE. What's Wrong with Terrorism? Cambridge, UK: Polity Press; 2006.

46. Mintrom M, Vergari S. Advocacy Coalitions, Policy Entrepreneurs, and Policy Change. Policy Studies Journal. 1996;24(3):420-434.

47. Manna P. School's In: Federalism and the National Education Agenda. Washington, DC, USA: Georgetown University Press; 2006.

48. McGuinn PJ. No Child Left Behind and the Transformation of Federal Education Policy, 19652000. Lawrence, KS, USA: University Press of Kansas; 2006.

49. Patashnik EM. Reforms at Risk: What Happens after Major Policy Changes Are Enacted. Princeton, NJ, USA: Princeton University Press; 2008.

50. Wilsford D. Path Dependency, or Why History Makes It Difficult but Not Impossible to Reform Health Care Systems in a Big Way. Journal of Public Policy. 1994;14(3):251-283.

51. Berkowitz ED. The Scenic Road to Nowhere: Reflections on the History of National Health Insurance in the United States. The Forum. 2010;8(1). doi: 10.2202/1540-8884.1350.

52. Skocpol T. Boomerang: Health Care Reform and the Turn against Government. New York, NY, USA: W.W. Norton and Company; 1996.

53. Hacker JS. The Road to Somewhere: Why Health Reform Happened. Perspective on Politics. 1996; 8(3):861-876.

54. Congleton RD. On the Political Economy of the Financial Crisis and the Bailout of 2008-2009. Public Choice. 2009;140(3/4):287-317.

55. Williams RA. Exogenous Shocks in Subsystem Adjustment and Policy Change: The Credit Crunch and Canadian Banking Regulation. Journal of Public Policy. 2009;29(1):29-53. 
56. Kuzmarov J. From Counter-Insurgency to Narco-Insurgency: Vietnam and the International War on Drugs. Journal of Policy History. 2008;20(3):344 378.

57. Whitford $A B$, Yates J. Presidential Rhetoric and the Public Agenda, Constructing the War on Drugs. Baltimore, MD, USA: Johns Hopkins University Press; 2009.

58. Miller LL. Rethinking Bureaucrats in the Policy Process: Criminal Justice Agents and the National Crime Agenda. Policy Studies Journal. 2004;32(4): 569-588.

59. Meier KJ, Smith KB. Say It Ain't So, Moe: Institutional Design, Policy Effectiveness, and Drug Policy. Journal of Public Administration Research and Theory. 1994;4(4):429-442.

60. Hosansky D. Food Safety: Is Our Food Supply as Safe as it Could Be? The CQ Researcher. 2002;12 (38):897-920.

61. Becker GS, Porter DV. The Federal Food Safety System: A Primer. Report RS22600, Updated 20 February 2007. Washington, DC, USA: Congressional Research Service; 2007.

62. U.S. Public Law 111-353. 4 January 2011.

63. Casey D. Agency Capture: the USDA's Struggle to Pass Food Safety Regulations. Kansas Journal of
Law and Public Policy. 1997;7:142-160.

64. Oliver JE, Lee T. Public Opinion and the Politics of Obesity in America. Journal of Health Politics, Policy and Law. 2005;30(5):923-954.

65. Kersh R, Morone J. The Politics of Obesity: Seven Steps to Government Action. Health Affairs. 2002;21(6):142-153.

66. Kersh R, Morone JA. Obesity, Courts, and the New Politics of Public Health. Journal of Health Politics, Policy and Law. 2005;30(5):839-868.

67. Pew Oceans Commission. America's Living Oceans, Charting a Course for Sea Change. Arlington, VA, USA: Pew Oceans Commission; 2003.

68. U.S. Commission on Ocean Policy. An Ocean Blueprint for the 21st Century. Final Report. Washington, DC, USA: U.S. Commission on Ocean Policy; 2004.

69. Chasis S. A Call for Ocean-Policy Reform. The American Prospect. 2008;19(12):A18-A20.

70. Brown KA. Critical Path: A Brief History of Critical Infrastructure Protection in the United States. Fairfax, VA, USA: Spectrum Publishing Group, Inc; 2006.

71. Dunn M. The Socio-Political Dimensions of Critical Information Infrastructure Protection (CIIP). International Journal of Critical Infrastructures. 2005; $1(2 / 3): 258-268$. 